\title{
Application of SolidWorks Plastic in the Training in Mechanical Engineering
}

\author{
Mariya Konsulova-Bakalova ${ }^{1}$ \\ 1-Technical University of Varna, Department of Machine Tools and Manufacturing, 9010, 1 Studentska Street, Varna, Bulgaria \\ Corresponding author contact: mbakalova@tu-varna.bg
}

\begin{abstract}
This article presents an example of applying SolidWorks in the training in mechanical engineering. The main features of the design of the parts intended for injection molding are mentioned. SolidWorks allows all these recommendations to be implemented when creating the details. The text explains the simulation settings that are made in SolidWorks Plastics when simulating injection molding. Through a specific example, it is referred to how making an analysis of the results obtained.
\end{abstract}

Keywords: SolidWorks Plastic, injection molding, mechanical engineering

\section{Introduction.}

Injection molding is a manufacturing process for producing parts by injecting into a mold cavity. Many things such as automotive and mechanical parts, storage containers, toys, and most other plastic products available today are created by injection molding. Injection molding is the most common method of producing plastic. That's why it is one of the manufacturing processes, which are necessarily studied by the mechanical engineering students.

The injection molding cycle is the sequence of events (Събев, 1989). It begins when the mold closes, followed by the injection of the polymer into the cavity through the runner system. When the mold cavity is filled, a pressure is maintained to compensate material's shrinkage. Once the material at the inlet has solidified, no more melt can enter into the cavity. This causes the preparation for the next injection shot to be started. Once the part is sufficiently cool, the mold opens and the part is ejected.

Like all manufacturing processes, injection molding can produce parts with possible production problems. Some of the possible defects are welding lines, sink marks, flow lines, air traps, warping etc. (Събев, 1989). They can be caused by defects in the molds or by the molding process.

One way to avoid flawed parts is to make a simulation of the molding process and the results of simulation analysis to assess whether the process settings and geometry of the mold are properly designed. This can be done with acceptable software.

There are numerous software programs for 3D modeling. In recent years, additional software modules have been added to the CAD software. Typically, these are modules that are used for different simulations. This is true for SolidWorks, which is traditionally used in education in mechanical engineering.

In the latest versions of SolidWorks, there is an opportunity to simulate the injection molding process. The purpose of this paper is to show an exemplary approach to solving a specific task of describing the injection molding process using SolidWorks Plastics. Such tasks are solved when designing molding tools and choosing the parameters of the injection molding process.

\section{$2 \quad$ Injection molding design with SolidWorks.}

There are many factors to consider for injection molding, but the part design and tool design are two of the most important (Тодоров, 2011). Getting them right could mean lower entry cost, high production quality, shorter cycle time, and quick assembly. Getting them wrong, on the other hand, can be very costly indeed. 
In order to have a successful design of tooling some recommendations must be for details design parts (cavity) on the one hand, and to choose the correct settings for the injection molding process on the other hand. Here are mentioned the main points when designing parts for injection molding and listed the stages of setting up a simulation with the SW Plastic.

\subsection{Design Recommendations:}

Some of the most fundamental guidelines when designing parts for injection molding are:

\subsubsection{Wall Thickness}

The thick walls can lead to long cycle times and poor mechanical properties. The thinner walls are,the easier in the injection molding process. The parts with thin walls cool faster, weigh less and use less plastic material per part. Injection molded parts should have a wall thickness that ranges from 2 $\mathrm{mm}$ to $4 \mathrm{~mm}$, but thin wall injection molding can go as thin as $0.5 \mathrm{~mm}$. Wall thickness also depends on the material used (see 3 Table1).

It is recommended, the wall thickness in injection-formed pieces are uniformly as well. This allows the mold cavity to fill more easily and helps avoid sink marks and warpage.

Table 1. Recommended wall thickness (Design Guidelines: Plastic Injection. Moulding, Proto labs, 2017).

\begin{tabular}{|c|c|}
\hline Material & Recommended wall thickness, mm \\
\hline ABS & $1.143-3.556$ \\
\hline Acetal & $0.762-3.048$ \\
\hline Acrylic & $0.635-12.7$ \\
\hline Liquid Crystal Polymer & $0.762-3.048$ \\
\hline Long-Fiber Reinforced Plastics & $1.905-25.4$ \\
\hline Nylon & $0.762-2.921$ \\
\hline Polycarbonate & $1.016-3.81$ \\
\hline Polyester & $0.635-3.175$ \\
\hline Polyethylene & $0.762-5.08$ \\
\hline Polyethylene Sulfide & $0.508-4.572$ \\
\hline Polypropylene & $0.635-3.81$ \\
\hline Polystyrene & $0.889-3.81$ \\
\hline Polyurethane & $2.032-19.05$ \\
\hline
\end{tabular}

\subsubsection{Corner Design}

Normally sharp corners are seen as stress concentrators. Other such places are a boss attached to a surface and strengthening ribs. The task is to reduce the sharp corners without increasing the wall thickness that it creates a sink problem. The stress concentration factor varies with radius for a given thickness (1):

$$
\mathrm{K}=\mathrm{R} / \mathrm{T}
$$

where $\mathrm{K}$ - stress concentration factor, $\mathrm{R}$ - corner radius, $\mathrm{T}$ - wall thickness.

For $\mathrm{K}$ values less than 0.5 the stress concentration factor is high and for $\mathrm{K}$ values over 0.5 the concentration lowers.

It is recommended, an inside radius to be a minimum of one time the thickness. At corners, the inside radius is 0.5 times the material thickness and the outside radius is 1.5 times the material thickness (see fig.1). A bigger radius should be used if the part design allows (Bolur, 2007).

Making the outside radius one wall thickness larger than the inside radius will maintain constant wall thickness through corners (Malloy, 2010):

$$
\mathrm{R} 2=\mathrm{R} 1+\mathrm{T}
$$




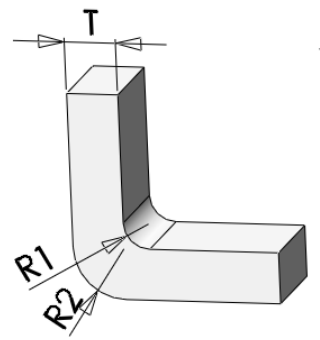

a) Good

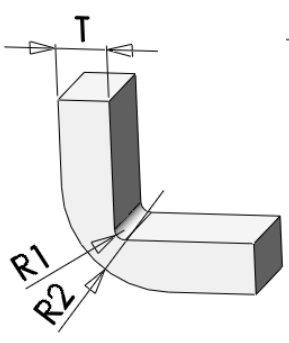

b) Too thin

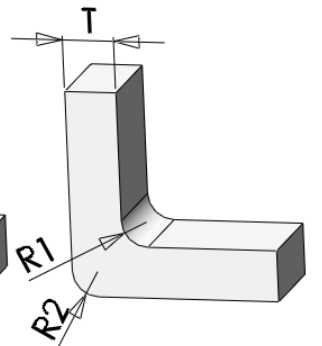

c) Too thick

Fig. 1. Radius Recommendation.

\subsubsection{Thickness Transitions}

The molten plastic does not have to be forced through varying restrictions as it fills. To achieve this, it is necessary to have uniform wall thicknesses. If this condition is fulfilled, the cavity can be easily filled. If design limitations make it impossible, the change in thickness should be as gradual as possible. When designing the parts, the rounding or tapering thickness transitions usually reduce stress concentration associated with abrupt changes in thickness.

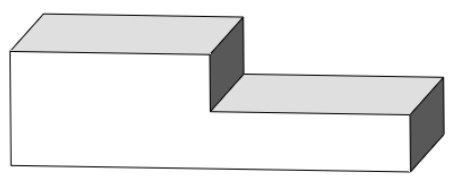

a) Incorrect

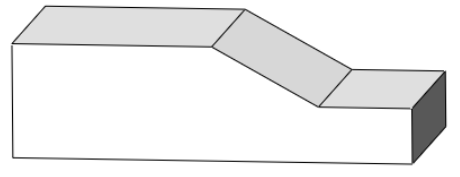

b) Correct

Fig. 2. Thickness Transitions.

\subsubsection{Ribs}

Ribs are used in a design to increase the bending stiffness of a part without adding thickness. The ribs should be designed so as not to make filling the cavity difficult. It is necessary to obverse the following requirements:

- Maximum rib thickness should be 0.5 to 0.75 of the wall thickness;

- The rib should be attached with corner radii;

- The distance between ribs should be at least two and a half times the nominal wall thickness.

- Ribs should have a draft angle of at least $0.5^{\circ}$ per side.

- Maximum rib height should be no greater than three times the nominal wall thickness in order to avoid large variations in wall thickness.

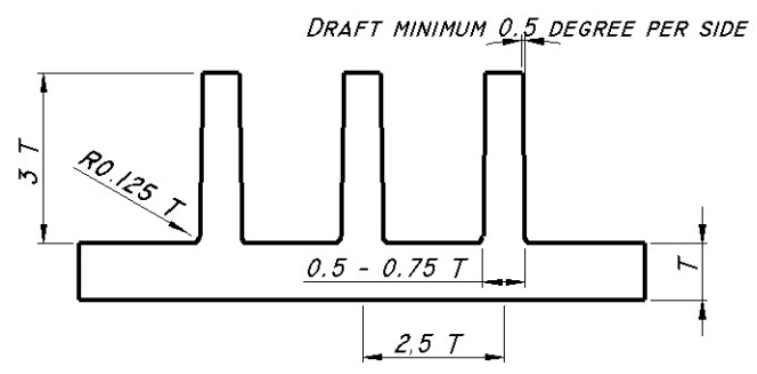

Fig. 3. Design guidelines for ribs. 


\subsubsection{Bosses}

Bosses are where fasteners, such as screws, are attached or threaded inserts are accepted When designing the bosses, the same requirements as the ribs are observed. It is necessary to avoid thick areas that can cause sink and voids in injection molded parts.

\subsubsection{Draft Angles}

To facilitate faster ejection, a draft angle of $1^{\circ}-3^{\circ}$ should be applied to all walls parallel to the parting direction of the clamping unit (Malloy, 2010).

\subsection{SolidWorks Plastic}

SolidWorks is a software program for 3D modeling. There is a Plastics application that simulates how melted plastic flows during the injection molding process. The main purpose of this application is to predict manufacturing defects on parts and molds. There is an Adviser that provides troubleshooting steps and helps diagnose potential problems. The injection molding simulation is performed with four analysis modules: Flow, Pack, Cool and Warp.

Flow analysis predicts how material fills the cavity. It accounts for heat transfer between the material (plastic) and mold (metal) during filling and predicts the changes in viscosity as material begin to solidify.

Pack analysis evaluates the material solidification process in the cavity. From flow and pack analysis, we can estimate optimal process conditions - filling time, injection pressure, pressure holding time, melt and mold temperature, and runner design, gate position, cavity thickness and mold material.

Warp analysis predicts shape and dimensions of the part after ejecting and cooling. The warp simulation is based on the finite elements method.

The simulation can be done with a wizard or manually. The wizard helps to select the mesh type and process parameters as materials and injection location. Once parameters are applied, the analysis can be launched and the results are interpreted.

The settings of the simulation are generating a mesh, choice of material, runners and cooling system design, settings of process parameters, choice of injection location and type of analysis that will be done.

\subsubsection{Generate mesh}

The plastic parts need to be meshed using shell or solid mesh. The shell mesh is the most useful for thin-walled parts (fig.4). It provides the best balance between analysis accuracy and computation time. The solid mesh provides accurate results for any type of models. There are two methods for meshing the geometry - automatic and manual. The manual method lets to set preferred mesh settings and improve the quality of the mesh.

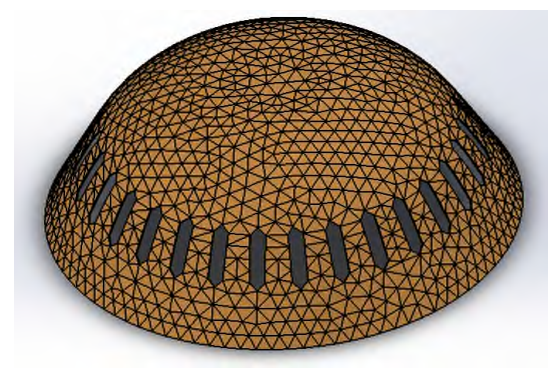

Fig. 4. Mesh model.

\subsubsection{Channel design}

In this section, there are settings for creating cooling channels or runner layouts. 
The runner layout can be made manually or with Channel design wizard. If it is done manually, it is necessary to have a sketch. The wizard does not need a sketch (fig. 5a).

The cooling channels (fig.5b) regulate the temperature of the melted part. They are located within the body of the mold. The cooling medium typically is water, or steam, oil. It is necessary to create a sketch to define the cooling channels.

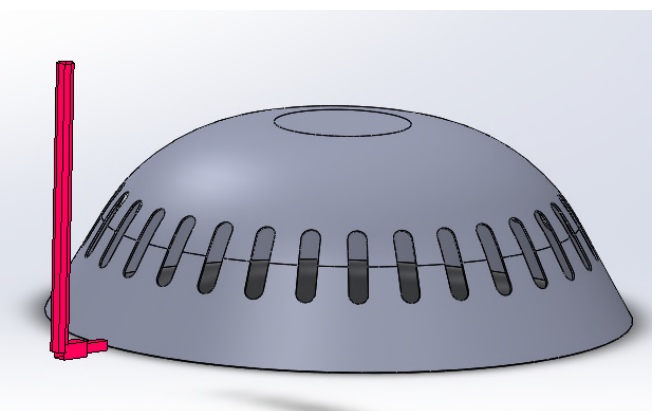

a) Runner layout

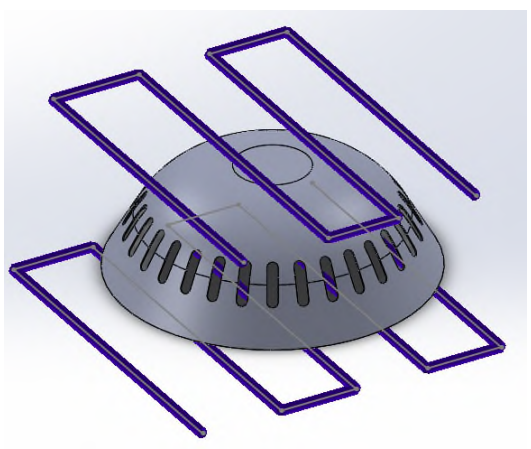

b) Cooling channels

Fig. 5. Channel design.

\subsubsection{Materials}

Choose the material for use with a part cavity and mold bodies. The material database provides access to thousands of materials and their properties: viscosity, specific heat, thermal conductivity etc.

\subsubsection{Process parameters}

Process parameters control how the material is injected into the cavity by specifying filling time, an injection flow rate, or screw velocity profile. If Auto is selected, the software applies the process parameters automatically. The SolidWorks Plastics calculates automatically the filling time based on the part geometry and the properties of the selected material (SOLIDWORKS Web Help).

The quality of a molded part depends upon the working material and the processing conditions. The injection pressure must be as high as necessary to fill the cavity sufficiently fast, completely and efficiently. But if the pressure is too high, however, there is a danger to produce high stressed injection molded components. The injection time must be selected to be just long enough to solidify the gate. If the injection time is too short, the compound can flow back out of the cavity, sink marks occur, and in general, there are larger tolerance variations. The correct injection time can be determined by weight measurement.

With injection times greater or equal to solidification time, the injection molded component weight remains practically the same. With injection times less than solidification time, the injection molded component weight decreases. If the flow stops before the mold has fully filled, the final molding weight will be lower. The sink marks indications that the injection time is shorter than the solidification time. In (Goodship, 2004) can find detailed information about the recommended values for these parameters.

Cool settings are used in the heat transfer analysis. The cool analysis predicts the distribution of temperature within the mold. The cooling process parameters are melt temperature, air temperature, min. coolant temperature, mold open time, cooling time (SOLIDWORKS Web Help). Cool simulation is finished after a fixed time - t. We can click Auto to populate a value based on a simple empirical formula (2), or enter own cooling time value.

$$
\mathrm{t}=\mathrm{d} .(1+2 . \mathrm{d})
$$

$\mathrm{t}$ - cooling time, $\mathrm{d}$ - wall thickness.

This value should be greater or equal to the sum of filling time and packing time.

\subsubsection{Injection Locations}


Injection locations are the locations where melted plastic flows from the runner system into the part cavity. The simulation model can have an injection system or not. If the injection system is included, the injection location is defined at the sprue inlet. If the model includes only a cavity, the injection locations are directly on the cavity. In this case, the effects of the injection system and gate geometry on the polymer temperature and flow are ignored.

Gate position can have a direct impact on part moldability, performance, appearance, and cost (Moayyedian, 2015). It should be positioned near the center of the part to balance filling and minimize the flow length (Engineering Plastics. Part and Mold Design. A Design Guide, 2007).

\subsubsection{Analysis type}

The analysis type can be Flow, Pack, Warp, Cool and combinations of them (SOLIDWORKS Web Help). When starting the simulation, an analysis manager appears. Here we can trace the stages of calculations. At the same time, we can see the cavity filled with plastic material if we choose Flow analysis.

\subsubsection{Results}

The results of the FLOW simulation include distributions of pressure and temperature within the cavity, the central temperature at the end of fill, shear stress, gate filling contribution and detection of weld lines, sink marks and air traps.

Pack results include distributions of pressure and temperature at the end of packing, stress, and shrinkage results. When it is done Warp analysis, can see the sink-mark profile.

There is a Result adviser. It indicates if the part can be successfully filled with an injection pressure.

\section{Example}

As an example detail to illustrate the designing of products with SolidWorks and SW Plastics will use a model of the children's constructor part (fig.6). The part was created in the SolidWorks. The material produced similar parts are acrylonitrile-butadiene-styrene, ABS (BASF Terlutan GP-35). This is a medium viscosity material with high quality- surface finish and gloss.

It is used the Thickness Analysis to determine different thicknesses of a part. The results are shown in fig.7a. The maximum thickness is about $3 \mathrm{~mm}$ within the limits of the recommended wall thickness for ABS (Table 1). There is a small area with a thickness less than the limits. In this area can be expected to have problems in filling the cavity. Ако налягането е твърде високо обаче, има опасност компонентите да са некачествени 


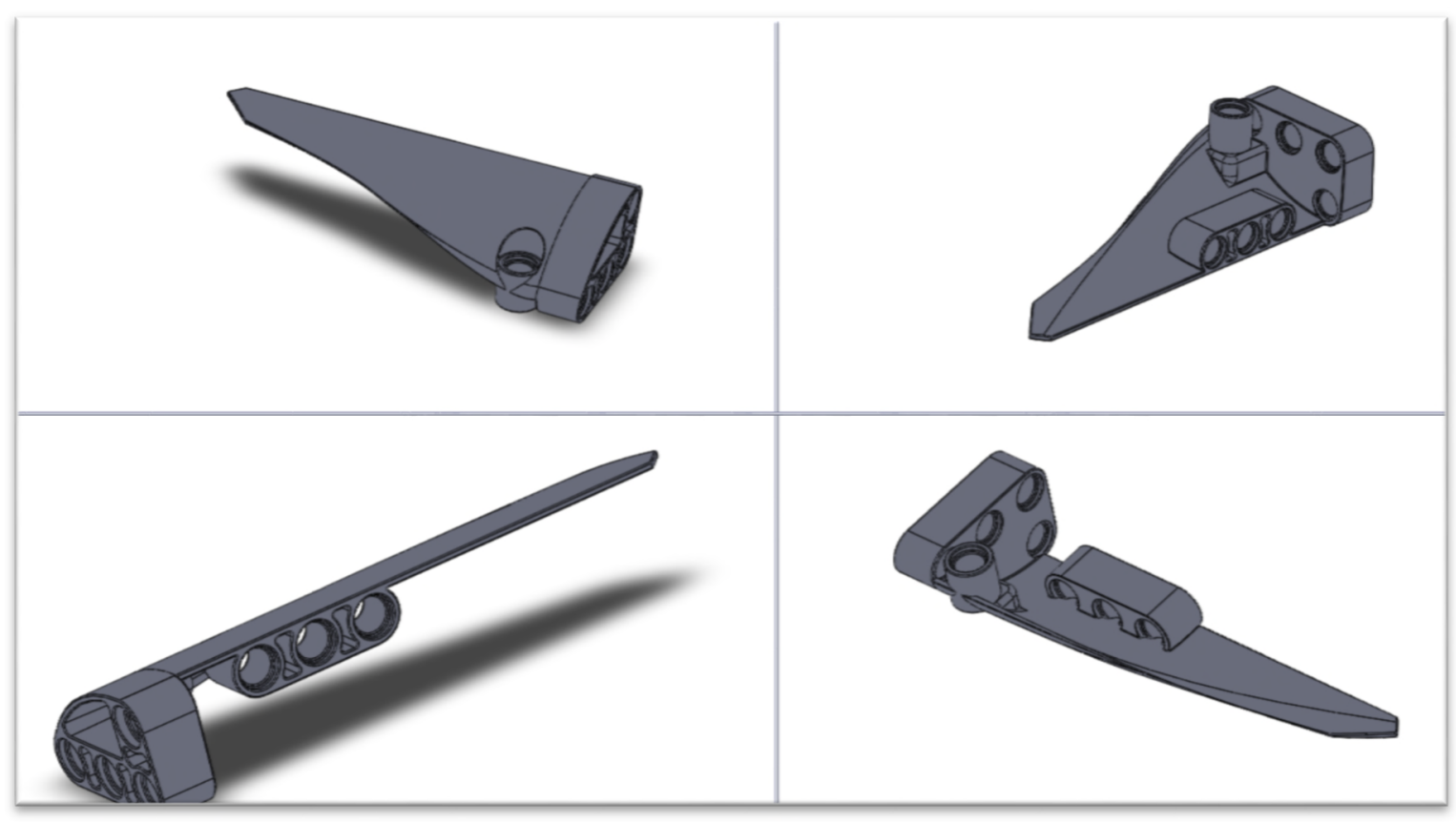

Fig. 6. SolidWorks model

Sharp corners of the part are radiused to reduce stress concentrators. The part is not with uniform thickness and changes in thickness are as gradual as possible. The draft angle is of $1^{\mathrm{O}}-3^{\mathrm{O}}$ (Консулова-Бакалова, 2013). The Draft Analysis (fig.7b) shows areas with a positive and negative draft.

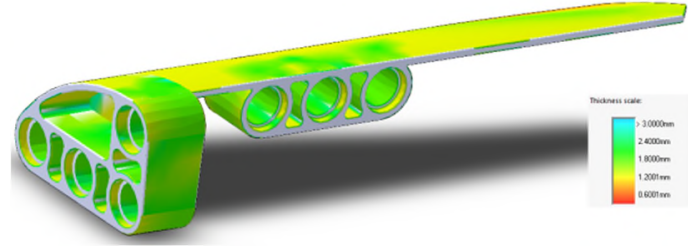

a) Thickness Analysis

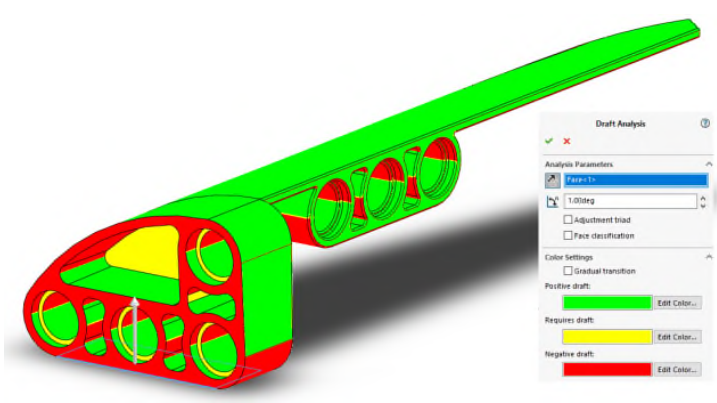

b) Draft Analysis

Fig. 7. Thickness and Draft Analysis.

The mesh type is shell (fig.8a). In this case, the part is with thin walls and complex geometric form, and shell mesh is the best choice. It was designed runner layout (fig. $8 \mathrm{~b}$ ). The gate location is selected in an area with a small variation in wall thickness to avoid non-uniform flow.

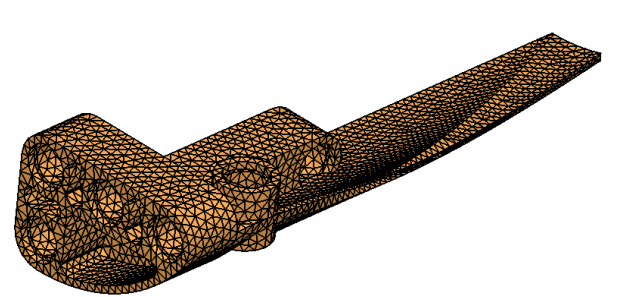

a) Meshed model in SW Plastics

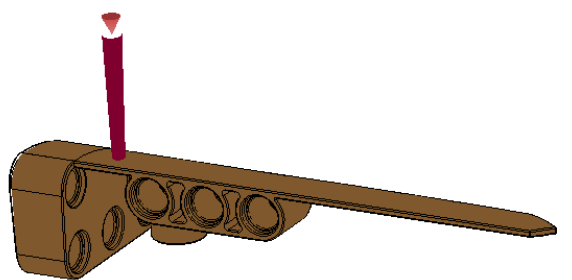

b) Gate position

Fig. 8. Simulation model.

Filling process parameters are: Melt Temperature $-248^{\circ} \mathrm{C}$; Mold Wall Temperature $-50^{\circ} \mathrm{C}$; Injection Pressure Limit - $250 \mathrm{MPa}$. Cool and warp settings are Ambient Temperature $-30^{\circ} \mathrm{C}$; Min. Coolant 
Temperature- $25{ }^{\circ} \mathrm{C}$; Eject Temperature- $83{ }^{\circ} \mathrm{C}$; Cooling Time - $6.58 \mathrm{sec}$. The injection time for medium viscosity materials is $0.25-0.5 \mathrm{~s}$ for injection volume $1-8 \mathrm{~cm}^{3}$ (Goodship, 2004). The volume of the part is $3.97 \mathrm{~cm}^{3}$ and the filling time is $0.5 \mathrm{~s}$.

The results of the simulation are shown in Fig.9 to Fig.15.

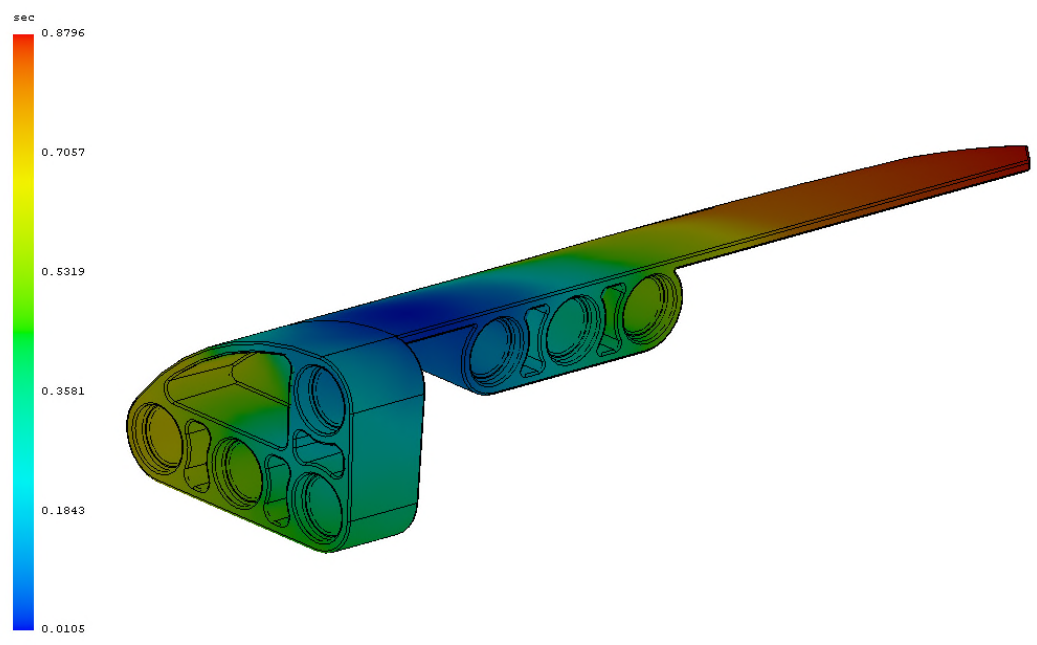

Fig. 9. Fill time

The plot of fill time (Fig.9) displays the profile of the plastic melt during the filling stage. The plot is animated. Another indicator of how the cavity has filled is the pressure at the end of fill (Fig.10). The fill time plot and the pressure at the end of fill plot help to clarify the injection locations. In this example, the pressure at the end of fill plot shows an uneven distribution of pressure throughout the part. But for this part repositioning the injection location does not improve the result. There is a difference in the wall thickness and asymmetry in detail. Pressure drop is a function of flow length, part wall thickness, and melt viscosity.

When the software detects uneven pressure distribution, we can change the fill time. A short fill time that means faster injecting, lowers the viscosity of the melted plastic and allowing the material to flow further. This may increase the injection pressure required. In this case, if we reduce the fill time by $0.88 \mathrm{~s}$ to $0.4 \mathrm{~s}$, the maximum pressure at the end of fill is reduced by $45.77 \mathrm{MPa}$ to $43.04 \mathrm{MPa}$.

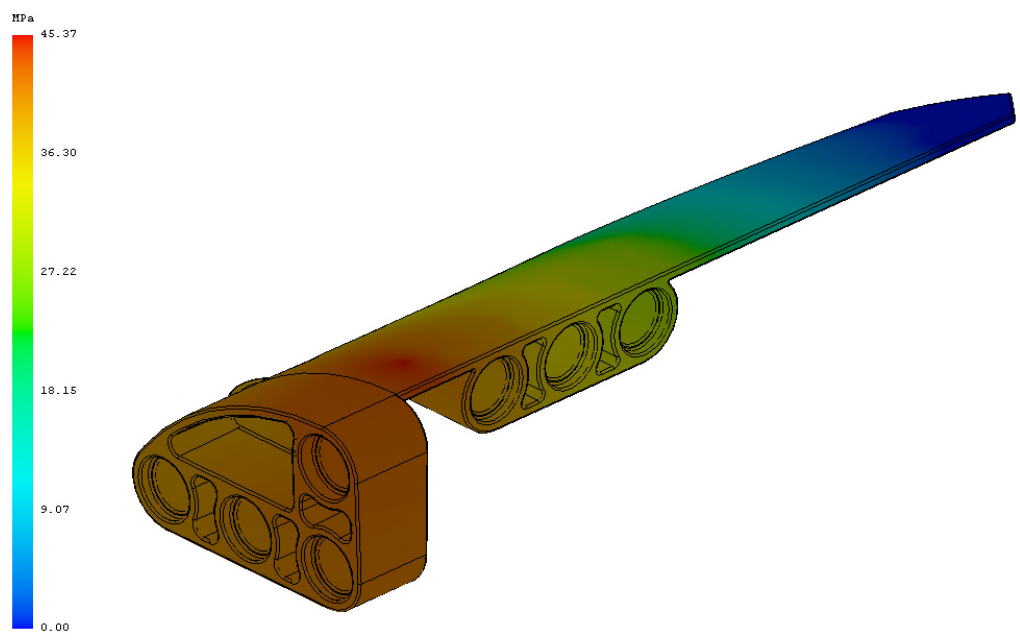

Fig. 10. Pressure at End of Fill

The central temperature at the end of fill plot (Fig.11) is the melt temperature of the central position between the two surfaces of a shell mesh. The plastic melts that is on the walls with greater thickness will retain heat for longer periods of time. 


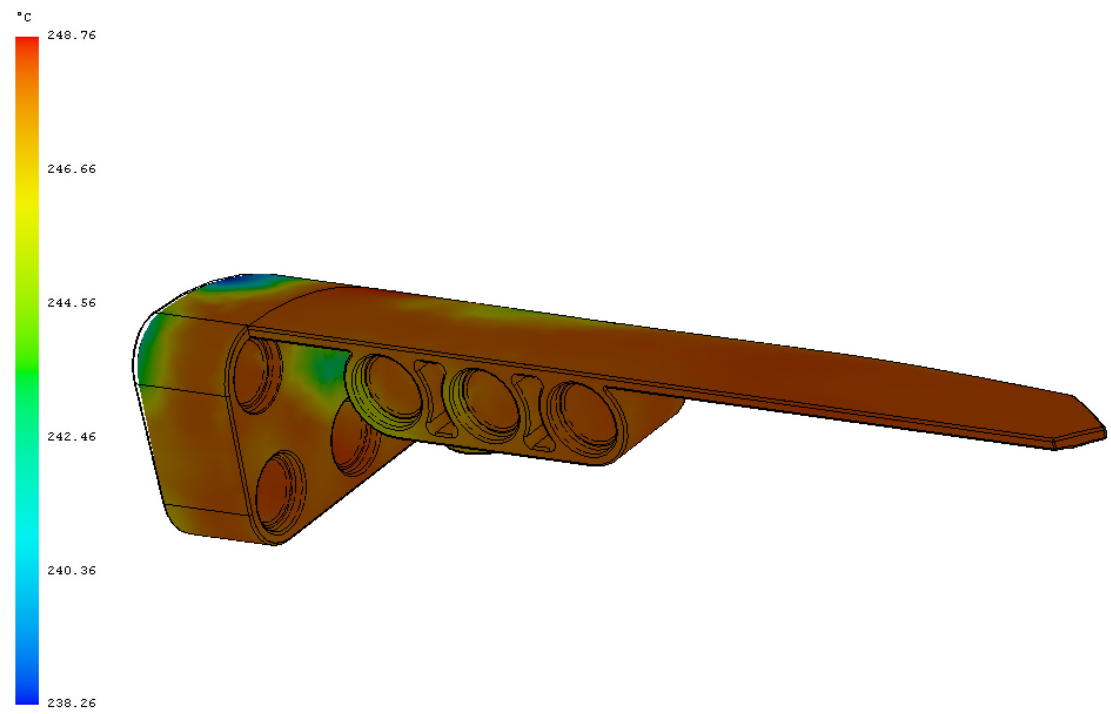

Fig. 11. Central Temperature at End of Fill

Shear rate (Fig.12) measures the velocity of a fluid layer passing over another layer of fluid at a different velocity. The shear rate should be less than the suggested maximum value for the plastic material. In this example, a max shear rate of material is $49500 \mathrm{~s}^{-1}$, greater than the calculated maximum values in the model $\left(44098.878906 \mathrm{~s}^{-1}\right)$. If we want to reduce shear rates, we can increase the fill time, which decreases the injection velocity.

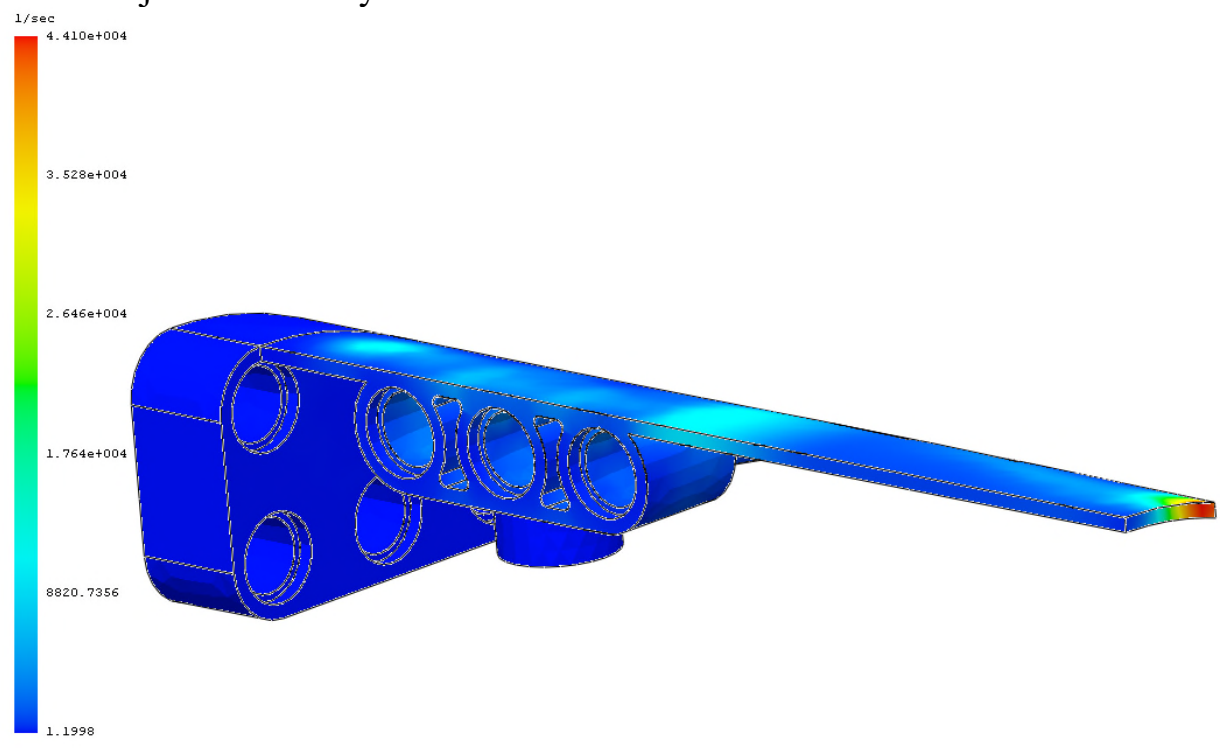

Fig. 12. Shear Rate at End of Fill.

Sink marks (Fig.13) are depressions on the surface of an injection molded plastic part. The main cause of sink marks is not enough polymer molecules have been packed into a cavity to compensate the shrinkage. Thicker sections of a part cool at slower than thinner sections. This results in greater shrinkage in the thicker areas. In this example to minimize sink marks, the injection location is in a thicker section of a part and the melted part is packed at higher pressure. In addition, injection location is not too small, which can prevent sufficient packing of the part cavity. 


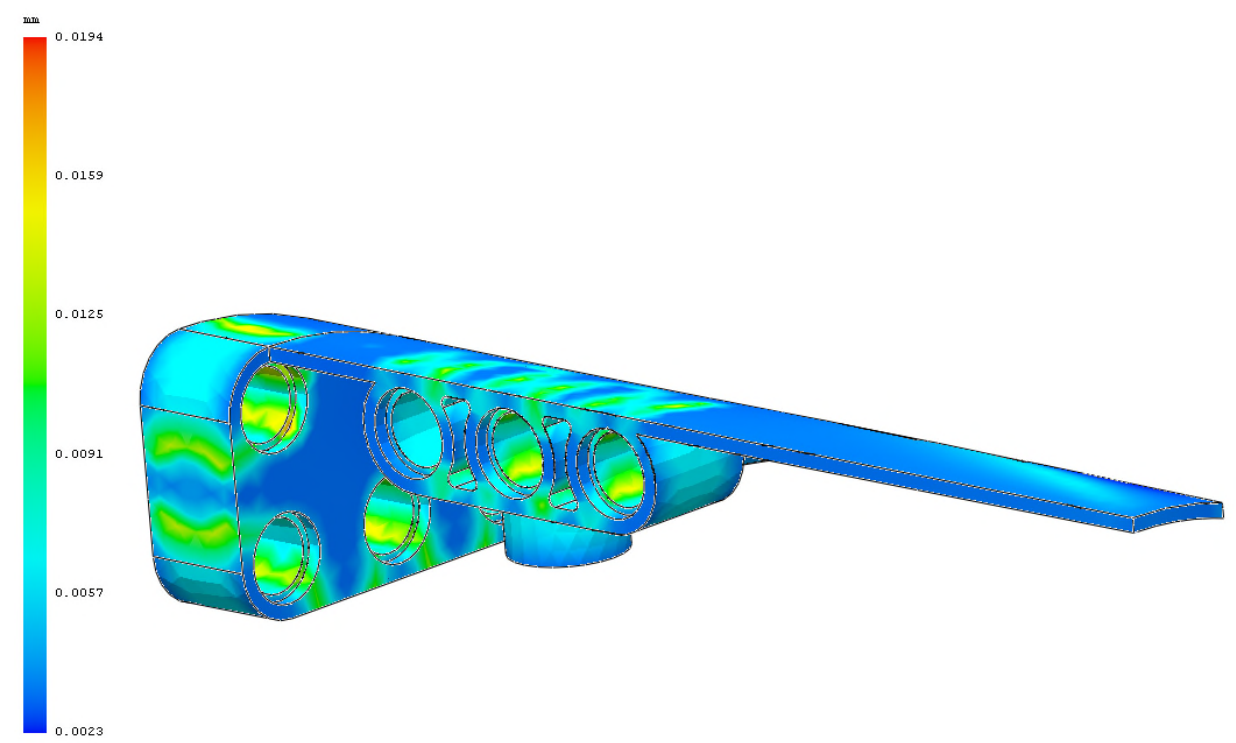

Fig. 13. Sink marks

Plastic materials are compressible because their specific volumes are a function of temperature and pressure. Higher rates of shrinkage will occur in areas of the plastic part that does not undergo a sufficient pack stage. If the Volumetric Shrinkage at End of Packing plot (Fig.14) indicates significant red areas this might result in voids or warpage. In this case, there are no such areas in the model.

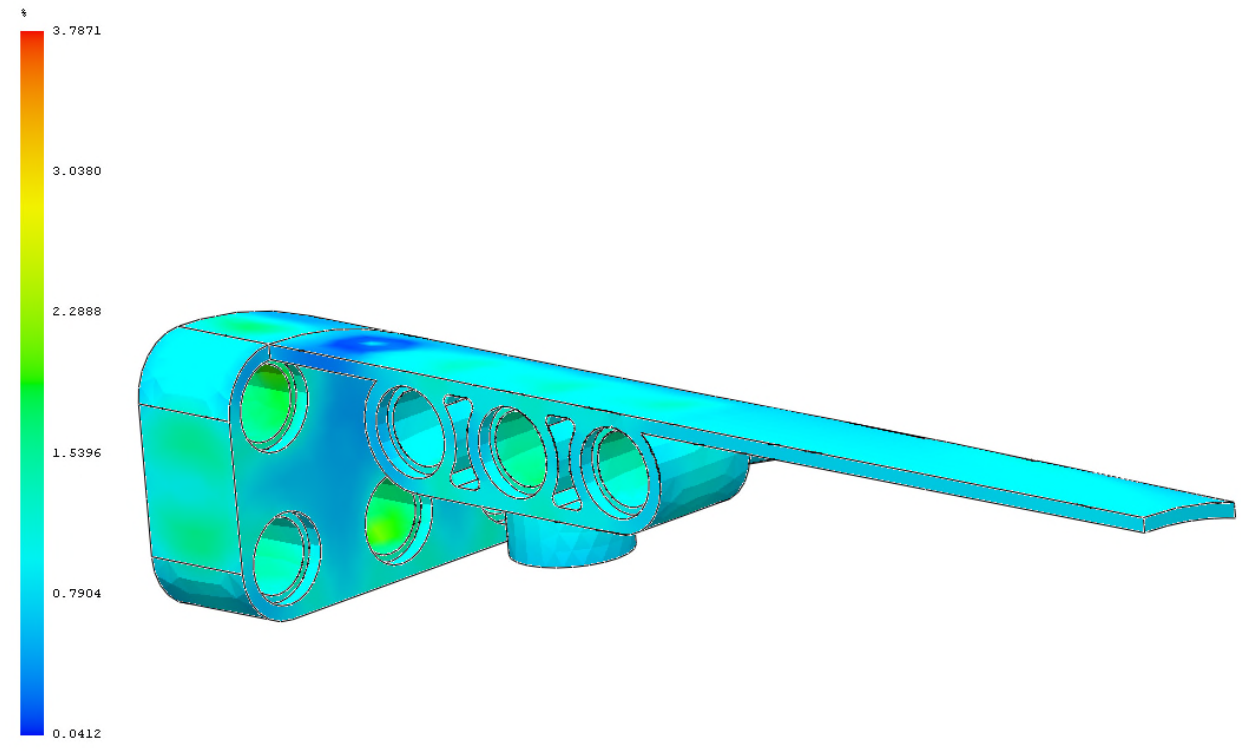

Fig. 14. Volumetric Shrinkage at the End of Packing.

To determine whether the cavity fills successfully we can use the ease of fill plot (Fig.15). The green regions indicate areas that can be filled under normal injection pressures. The yellow regions are areas where the injection pressure is 70 percent of the machine's maximum injection pressure. In the red regions, the injection pressure is 85 percent of the machine maximum injection pressure. The plot shows, that the part can fill easily under normal injection pressure. 


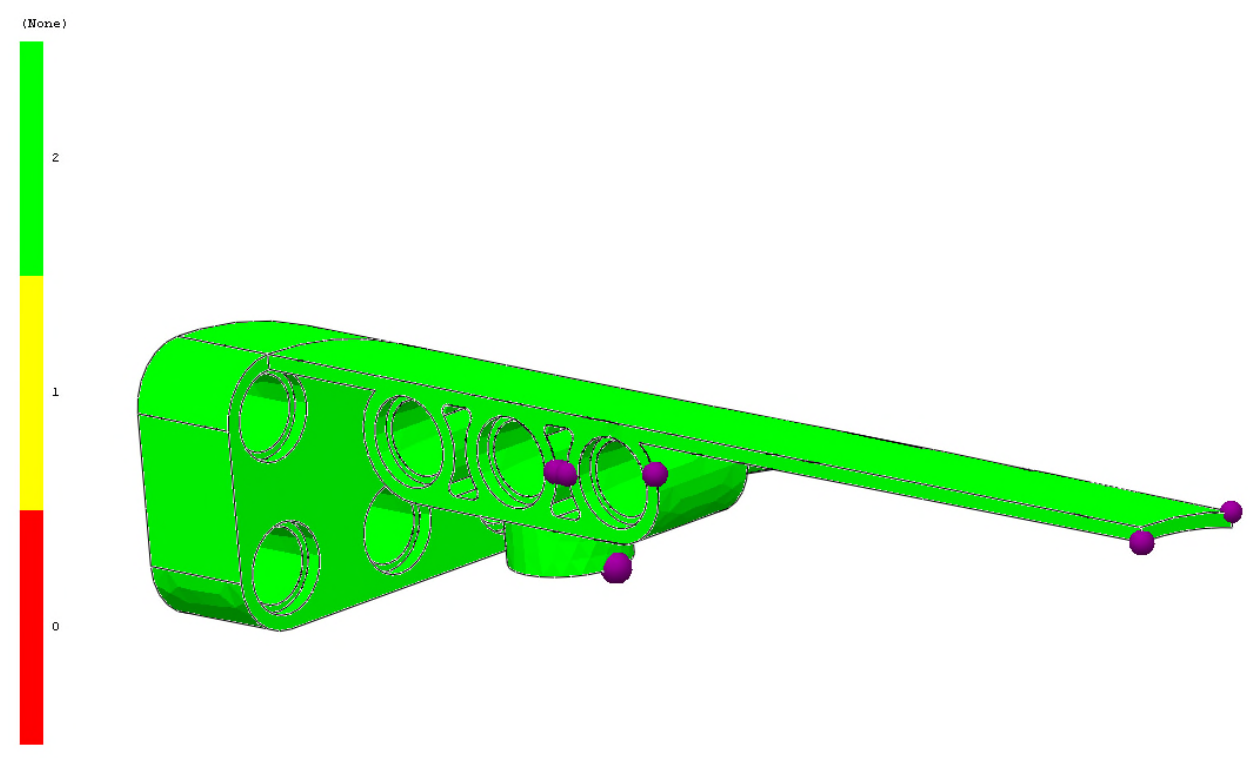

Fig. 15. Easy to Fill and Air Traps

Injection Molding Air Traps occur when a bubble of air is trapped as plastic flow fronts coincide. The air trap can cause various defects in a plastic part such as blemishes on the surface, incomplete filling, and packing. The image (Fig.15) depicts an air trap location detected during simulation using SW Plastics. There should be vents provide for the removal of air from the cavity.

This part can be successfully filled with an injection pressure of $67.5 \mathrm{MPa}$. The injection pressure required to fill is less than $66 \%$ of the maximum injection pressure limit specified for this analysis, which means it is under your specified limit. $140 \mathrm{MPa}$ is the maximum injection pressure limit of most commercial injection molding machines. Since the maximum injection pressure limit is greater than this value, this is generally considered a high-pressure molding process that may require a special screw and barrel combination or high-pressure injection molding machine. There is little to no risk of plastics material degradation since the temperature at the end of fill has remained within $10^{\circ} \mathrm{C}$ of the starting melt temperature.

\section{Conclusions}

In the present paper are listed some of the basic features in designing injection molding parts (plastic products) with using the SolidWorks. In mechanical engineering training, the study of the production of plastic products is a main area. The use of SolidWorks Plastics design details is very comfortable and gives good possibilities to find possible defects still in the design stages before there is a realmade product.

The proposed example gives the opportunity to explore more complex models and suggests ways to avoid problems in designing of runner system and setting up the parameters of the injection molding process.

Each of the stages of the design process can be considered as a separate task and to be explored more thoroughly. The method would be useful in the training of students who are familiar with 3D modeling with SolidWorks and study the methods of performing simulations.

\section{References}

Bolur P.C. (2007). A Guide to Injection Moulding of Plastics-3rd Edition. ISBN-13: 978-8190223522. Available from https://www.pitfallsinmolding.com/index.html

Design Guidelines: Plastic Injection. Moulding, Proto labs (2017). Available from https://www.protolabs.co.uk/resources/design-tips/ 
Engineering Plastics. Part and Mold Design. A Design Guide (2007). LANXESS Corporation. U.S.A. www.US.LANXESS.com

Goodship V. (2004). ARBURG - Practical Guide to Injection Moulding. Rapra Technology Limited Shawbur. Shrewsbury, Shropshire, SY4 4NR, UK. ISBN: 1-85957-444-0

Malloy R.A. (2010). Plastic Part Design for Injection Molding. Hanser Publishers, Munich. ISBN 978$1-56990-436-7$

Moayyedian M., K. Abhary, R. Marian (2015). Improved gate system for scrap reduction in injection molding processes. 2nd International Materials, Industrial, and Manufacturing Engineering Conference, MIMEC2015,4-6 February 2015, Bali Indonesia. Procedia Manufacturing 2. 246 -250p., doi: 10.1016/j.promfg.2015.07.043

\footnotetext{
SOLIDWORKS Web Help (2017). Available from http://help.solidworks.com/2018/English/swplastics/c_SOLIDWORKS_Plastics_Welcome.ht $\mathrm{m}$
}

Консулова-Бакалова М., Гр. Василев (2013). Методика за топлинно моделиране на инструментална екипировка. Х Международен конгрес „Машини, Технологии, Материали“ 2013. 18-20 септември 2013, Варна. сборник с доклади Volume 2: Section Machines, Section Technologies. стр.27-30

Събев П., Б. Вангелов (1989). Шприцформи и пресформи. Техника, София

Тодоров Г., Г. Николчева (2011). Компютърно проектиране и бързо изработване на формообразуващи инструменти със сложни повърхнини. ТУ-София. ISBN 978-954-438-915-4 